\title{
Oxiesteroles: efectos biológicos; formación, contenido y determinación en alimentos.
}

\author{
Por F. Guardiola, M. Rafecas, R. Codony y J. Boatella*. \\ Unidad de Nutrición y Bromatología. Departamento de Ciencias Fisiológicas Humanas y de la \\ Nutrición. Facultad de Farmacia. Universidad de Barcelona. \\ Avda. Diagonal, s/n. 08028 - Barcelona.
}

\section{RESUMEN}

Oxiesteroles: efectos biológicos; formación, contenido y determinación en alimentos.

Se realiza una revisión bibliográfica de los aspectos nutricionales y bromatológicos de los llamados oxiesteroles. Se recogen los efectos biológicos descritos para estos compuestos, su presencia y formación en alimentos y la metodologia analitica para su determinación.

PALABRAS-CLAVE: Alimento - Análisis - Efecto biológico - Información (articulo) - Oxiesterol.

\section{SUMMARY}

Cholesterol oxidation products: biological effects; formation, content and determination in food.

We make a bibliographical review on the main aspects related to the cholesterol oxidation products, including their biological effects, their presence and formation in food and their analytical determination.

KEY-WORDS: Analysis - Biological effect - Cholesterol oxidation product - Food - Information (paper).

\section{INTRODUCCION}

Sobre la molécula de colesterol (colest-5-en-3ß-ol) (Fig. 1) pueden producirse fenómenos oxidativos, ya sea por vía enzimática o por mecanismos de autooxidación. Ambos procesos conducen a la formación de un gran número de derivados, entre los cuales, los denominados oxiesteroles (OE) se caracterizan por

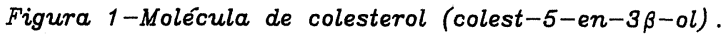

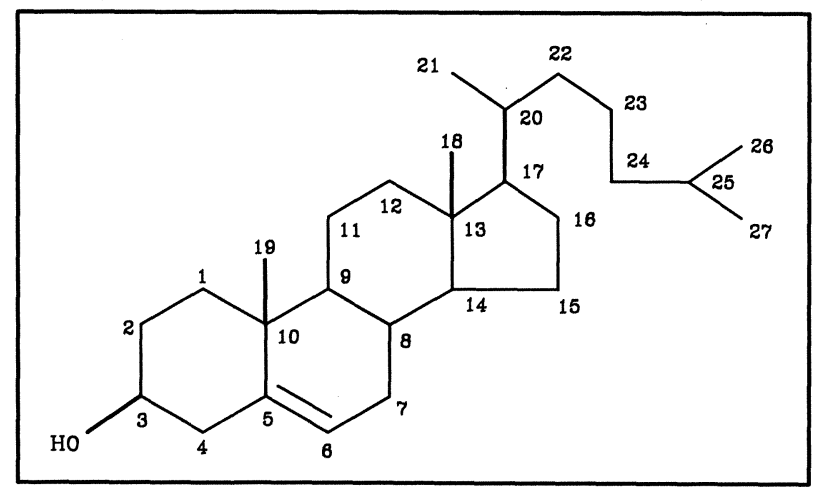

poseer una o varias funciones de tipo alcohol, cetona, peróxido y/o epóxido (Tab. I).

La oxidación enzimática de esta molécula acontece básicamente a nivel hepático y de los tejidos generadores de hormonas esteroideas, produciéndose por hidroxilasas ( $7 \alpha$-hidroxilasa y 26 -hidroxilasa) localizadas en el hepatocito (21) (30) (37) y por complejos enzimáticos ubicados en las mitocondrias de los tejidos esteroidogénicos (21) (26) (30) (32) (61). Mediante estos procesos se originan una serie de compuestos ( $7 \alpha-\mathrm{HC},(22 \mathrm{R})-22-\mathrm{HC}, 26-\mathrm{HC}$, etc), que son intermediarios metabólicos en la síntesis de ácidos biliares y de hormonas esteroideas.

Por otra parte, los fenómenos de autooxidación del colesterol se conocen desde principios de siglo, cuando SCHULZE y WINTERSTEIN (66) constataron que esta sustancia en su forma cristalina sufría un proceso de transformación, como consecuencia de su exposición a radiaciones solares. Posteriormente, BERGSTRÖM Y WINTERSTEINER (6) (7) (8) comprobaron la naturaleza oxidativa del fenómeno. Pero hicieron falta aún varios años para llegar a la conclusión de que este proceso se produce por un mecanismo radicalario (31) (49) que da lugar a la formación de hidroperóxidos (31) (42) (49) (74) (75) compuestos químicamente lábiles que se descomponen de forma secundaria en una amplia gama de productos (Fig. 2), de los cuales SMITH, en 1981 (69), consiguió aislar e identificar total o parcialmente más de 70 .

La formación de estos derivados en alimentos, puesta ya de manifiesto por ACKER Y GREVE en 1963 (1), obedece a las diferentes condiciones a que éstos se someten, ya sea durante su elaboración (31) (44) (46) (48) (49) (53) (55) (65) (77) (78) o bien a lo largo de su almacenaje (46) (48) (49) (65) (78), siendo especialmente notable en aquellos productos con una mayor densidad de colesterol (65).

Por extensión del tema, deben tomarse también en consideración los productos de autooxidación procedentes de los distintos fitosteroles, compuestos 
Tabla I-Nomenclatura y fórmula estructural de los principales $O E$ detectados en productos alimenticios.

\begin{tabular}{|c|c|c|}
\hline Nombres sistemáticos & Nombres vulgares & Fórmula estructural \\
\hline 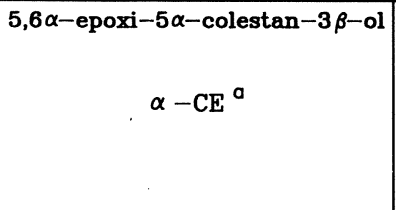 & $\begin{array}{l}\text { Colesterol- } 5 \alpha, 6 \alpha \text {-epóxido } \\
\alpha \text {-epoxido de colesterol } \\
5 \alpha, 6 \alpha \text {-epoxicolestanol } \\
\text { Colesterol } \alpha \text {-óxido } \\
\alpha \text {-epoxicolesterol } \\
5 \alpha, 6 \alpha \text {-epóxido } \\
\alpha \text {-epóxido }\end{array}$ & \\
\hline 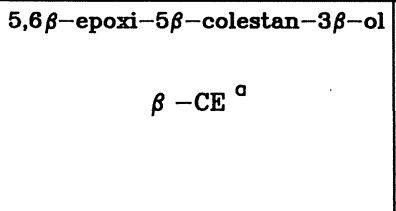 & $\begin{array}{l}\text { Colesterol- } 5 \beta, 6 \beta \text {-epóxido } \\
\beta \text {-epóxido de colesterol } \\
5 \beta, 6 \beta \text {-epoxicolestanol } \\
\text { Colesterol } \beta \text {-óxido } \\
\beta \text {-epoxicolesterol } \\
5 \beta, 6 \beta \text {-epóxido } \\
\beta \text {-epóxido }\end{array}$ & \\
\hline $\begin{array}{c}\text { Colest-5-en-3 } \beta, 7 \alpha \text {-diol } \\
7 \alpha-\mathrm{HC}^{\alpha}\end{array}$ & $7 \alpha$-hidroxicolesterol & \\
\hline 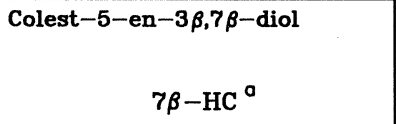 & $7 \beta$-hidroxicolesterol & \\
\hline $\begin{array}{c}\text { Colest-5-en-3 } \beta, 25-\text { diol } \\
25-\mathrm{HC}^{a}\end{array}$ & 25-hidroxicolesterol & \\
\hline $\begin{array}{c}5 \alpha-\text { colestan }-3 \beta, 5,6 \beta-\text { triol } \\
\mathrm{CT}^{a}\end{array}$ & $\begin{array}{l}\text { Colestan-triol } \\
\text { Colestantriol }\end{array}$ & \\
\hline $\begin{array}{c}3 \beta \text {-hidroxicolest-5-en-7-ona } \\
7 \text { - } \mathrm{CC}^{\circ}\end{array}$ & 7-cetocolesterol & \\
\hline
\end{tabular}

a Símbolo.

éstos, que se hallan mucho menos estudiados. A este respecto, se mencionan (81) productos de oxidación del sitosterol, tales como: estigmast-5-en-3ß,7 $\alpha$-diol, estigmast-5-en-3B,7B-diol, etc, formados en diversos modelos experimentales.

En relación con los efectos biológicos de los $O E$, fue a finales de los años 60 cuando BISCHOFF (9) demostró que el colesterol- $5 \alpha, 6 \alpha$-epóxido, administrado subcutáneamente en ratas y ratones, inducía la formación de tumores. Un poco más tarde, KANDUTSCH Y CHEN (37) constataron la capacidad de ciertos oxiesteroles $(7 \alpha-\mathrm{HC}, 7 \mathrm{~B}-\mathrm{HC}$, y $7-\mathrm{CC})$ para inhibir la sintesis del colesterol. El conocimiento de estos efectos y la presencia demostrada de OE en alimentos son aspectos que plantean el tema de las reper. cusiones nutricionales de estos compuestos y justifican el interés creciente de esta cuestión.

Por último y en función de todo ello, aparece una nueva faceta en relación con este tema, ya que la formación de estas sustancias en algunos alimentos, como consecuencia de la aplicación de diferentes tratamientos o condiciones de conservación, podría ser un parámetro de interés en el control de calidad de los mismos. 
Figura 2-Autooxidación del colesterol (refs. 74 y 75).

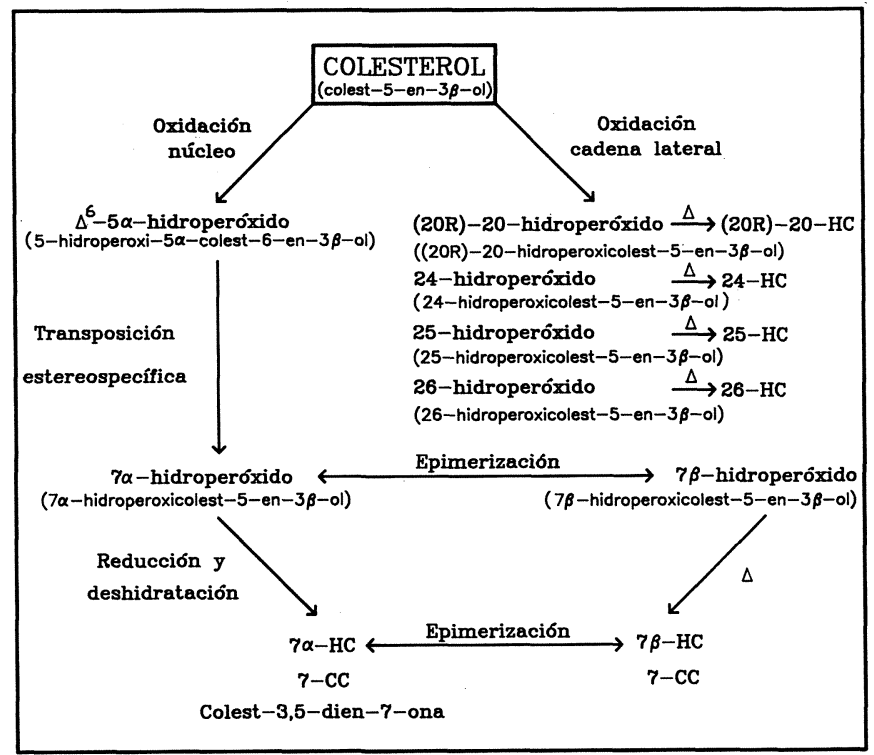

\section{EFECTOS BIOLOGICOS}

Los efectos biológicos de los diferentes OE, ya sean metabolitos intermedios en la síntesis de ácidos biliares y hormonas esteroideas o productos originados autooxidativamente a partir del colesterol, no están bien establecidos e incluso, en algunos casos, son objeto de controversia.

En la Tabla II se recogen los principales $O E$ detectados en productos alimenticios y los efectos biológicos relacionados.

Uno de los efectos estudiados con mayor profundidad es el de la acción inhibidora de algunos de estos compuestos sobre la actividad de la HMG-CoA reduc- tasa, enzima que como es sabido regula la etapa limitante en la sintesis de colesterol (14) (15) (17) (18) (37) (39) (72). A pesar de los muchos trabajos referentes a este punto, el mecanismo de acción por el cual los OE inhiben a la HMG-CoA reductasa no es del todo conocido. Se sabe que este enzima puede encontrarse en el organismo bajo dos formas, una fosforilada (inactiva) y otra sin fosforilar (activa). Por ello, podría pensarse que los OE actuaran sobre este proceso de fosforilación, pero algunos estudios referentes a este punto revelan, que este no es el verdadero mecanismo de acción (17) (72). Gracias a los trabajos de diferentes investigadores, se han descartado también del posible mecanismo que conduce a

Tabla II-Principales $O E$ detectados en productos alimenticios y efectos biológicos relacionados.

\begin{tabular}{|c|c|c|c|c|c|c|}
\hline $\mathrm{OE}_{\text {biol }}^{\text {Efecto }}$ & $\begin{array}{l}\text { Inhibicion de } \\
\text { HMG-CoA reduc. }\end{array}$ & Aterogenesis & Carcinogênesis & Mutagénesis & Citotoxicidad & Asociaciôn a DNA \\
\hline$\alpha-C E$ & $\stackrel{+}{+}$ & $\begin{array}{c}+ \\
(29,33,34 \\
\text { y } 79) \\
\end{array}$ & $\begin{array}{l}+ \\
(9,10,11,12, \\
16,70 \text { y } 79)\end{array}$ & $\left(13^{+}\right.$y 68$)$ & - & $(13 \stackrel{+}{\text { y }} 54)$ \\
\hline$\beta-C E$ & - & - & - & - & - & - \\
\hline $7 \alpha-\mathrm{HC}$ & $\left(17^{+}\right.$y 37$)$ & $\stackrel{+}{(58)}$ & - & - & - & - \\
\hline $7 \beta-\mathrm{HC}$ & $(17 \stackrel{+}{\mathrm{y}} 37)$ & $\stackrel{+}{+}$ & 一 & 一 & $\stackrel{+}{+}$ & 一 \\
\hline $25-\mathrm{HC}$ & $\begin{array}{cc} & + \\
(14, & 15,17 \\
18 & y\end{array}$ & $\begin{array}{c}+ \\
(2,33,57 \\
y 58)\end{array}$ & - & - & - & - \\
\hline CT & - & $\left(2,33^{+}\right.$y 58$)$ & - & - & - & - \\
\hline $7-C C$ & $(14, \stackrel{+}{17}$ y 37$)$ & $\left(33^{+}\right.$y 58$)$ & - & - & - & - \\
\hline
\end{tabular}

$+\quad$ Efecto citodo (refs.).

- Efecto no citado en la bibliografía consultado. 
esta inhibición: la acción directa sobre el enzima (17) (59), la actuación a nivel de permeabilidad de membrana (17), la modificación de la síntesis de RNA (17) (37) o de proteínas (37) y la alteración del metabolismo del acetato hacia $\mathrm{CO}_{2} \mathrm{O}$ ácidos grasos (37). Sin embargo, varios autores coinciden en la observación de que estos compuestos producen una disminución de los niveles de HMG-CoA reductasa en diferentes modelos celulares (18) (37) (72). Esta disminución es debida, para algunos de estos autores, a un decremento en la síntesis del enzima (18) (37), mientras que para otros, se produce además un aumento en su degradación (72). También se acepta el hecho de que esta actividad inhibidora se encuentre asociada a caracteres estructurales específicos (14) (37) (55)

Junto a este efecto sobre la HMG-CoA reductasa, existen numerosos estudios que atribuyen a compuestos de esta naturaleza acciones biológicas diversas, entre las cuales, las más estudiadas son:

Aterogénesis: Este efecto se ha demostrado en distintas condiciones experimentales, para una serie de oxiesteroles ( $\alpha-C E, 25-H C, C T$, etc). En el caso del $\alpha$-CE existen opiniones contrapuestas en relación a esta acción, ya que mientras algunos investigadores consideran que el compuesto es aterogénico "per se" (29) (33) (34) (79), otros en cambio, como MISSLER y cols. (44), atribuyen esta propiedad de forma exclusiva a su producto de hidrólisis, que no es otro que el colestantriol, compuesto en el que sí hay acuerdo sobre sus propiedades aterogénicas (2) (33) (58). Este hecho enunciado por MISSLER y cols., ya había sido puesto de manifiesto anteriormente como una posibilidad, por PENG y cols. (56). Por otra parte, en diversos trabajos se han encontrado en el suero de personas hipercolesterolémicas concentraciones anormalmente altas de $\alpha$-epóxido, que no se observan en individuos que no padecen esta afección (29). En relación con este aspecto, se ha comprobado que el 26-HC se encuentra formando parte de la fracción esterólica de los lípidos extraídos a partir de lesiones ateroscleróticas aórticas humanas (28).

Carcinogénesis: Esta actividad ha sido únicamente detectada en el caso del colesterol- $5 \alpha, 6 \alpha$-epóxido. BISCHOFF, ya en 1969 (9), comprobó que este compuesto administrado subcutáneamente inducía la formación de tumores en ratas y ratones. Más tarde, este producto se aisló de piel humana (12) (16) y de ratones (11) irradiada con luz UV. En este último caso se observó que un aumento en los niveles de $\alpha$-epóxido se traducía rápidamente en un incremento de la incidencia del cáncer de piel en estos animales (16). Este mismo equipo confirmó la existencia de esta relación causal en un trabajo posterior (10).
Mutagénesis: Esta es otra de las acciones únicamente comprobada (13) (68) para el colesterol-5 $\alpha, 6 \alpha$ epóxido, pero en este caso los resultados experimentales son discutidos por diversos autores (36) (41) (71).

Acciones sobre membrana: En diferentes cultivos celulares, se ha observado que la adición de ciertos $\mathrm{OE}$ inhibidores de la síntesis de colesterol va acompañada de una reducción en la tasa de crecimiento celular (14) (17). Esto, para CHEN y cols. (17), puede ser debido a una inestabilización de la membrana. En relación con ello, KANDUTSCH y cols. en 1978 (39), establecieron que los OE inhibidores de la HMG-CoA reductasa conducian a una disminución del contenido de colesterol a nivel de membrana, fenómeno que podria afectar al proceso de reproducción celular. Esta posibilidad ha sido últimamente descartada por CRASTES de PAULET y cols. (21). Por otro lado, cabe destacar que un descenso de la concentración de colesterol en la membrana conlleva un aumento de su fluidez, con lo cual resultan afectados el transporte y la actividad de enzimas a este nive! (17) (55).

Además de todas estas acciones, en la bibliografía consultada, se citan otras relacionadas con algunas de las ya comentadas, tales como: Citoxicidad (62) y asociación a DNA (13) (54).

\section{FORMACION: FACTORES QUE INTERVIE- NEN}

Los factores que influyen en la formación de oxiesteroles en productos alimenticios son múltiples, pero según SANDER y cols. (65), los más importantes son: temperatura, radiaciones, fotosensibilizantes, iones de metales de transición, tiempo de almacenaje, $\mathrm{pH}$ y concentraciones de colesterol.

No obstante, también se han realizado estudios referentes a la influencia de la adición de sal (65) a sustratos, presencia de prooxidantes (46) y antioxidantes (46) (53) (55), así como respecto a sistemas de secado, utilizados en la obtención de algunos preparados alimenticios (44) (46) (48) (49) (77) (78).

Por último, cabe citar algunos trabajos que estudian la formación de OE en sebos (4) (53) (55) (63) (64) y mantequillas (65) (22), cuando estos productos son calentados a altas temperaturas durante períodos de tiempo variables. El interés de estos trabajos radica en el hecho de que permiten evaluar la autooxidación del colesterol, en condiciones similares a las que son sometidos estos productos cuando se utilizan como medios de fritura

La presencia de OE ha sido puesta de manifiesto en distintos productos alimenticios, entre los cuales destacan algunos derivados lácteos (49) (65), ovoproductos (31) (44) (46) (47) (48) (55) (77) (78) 
(79), productos cárnicos (52) y alimentos sometidos a fritura (52) (63).

Las especies más frecuentemente detectadas en productos alimenticios son las siguientes: $\alpha-C E, \beta-$ $\mathrm{CE}, 7 \alpha-\mathrm{HC}, 7 \mathrm{~B}-\mathrm{HC}, 25-\mathrm{HC}, \mathrm{CT}$ y $7-\mathrm{CC}$. Como puede apreciarse en las tablas III, IV, V, los contenidos de estos compuestos varían en función de las características del producto, de los procesos tecnológicos aplicados y del tiempo y de las condiciones de conservación y almacenaje.

Tabla III-Formaciôn de OE (ppm) en quesós sometidos a diferentes periodos $y$ condiciones de almacenaje (ref. 65).

\begin{tabular}{|c|c|c|c|c|c|c|c|c|c|c|}
\hline & \multicolumn{2}{|c|}{ Contenido inicial } & \multicolumn{4}{|c|}{ Almacenados 3 meses } & \multicolumn{4}{|c|}{ Almacenados 6 meses } \\
\hline & \multirow[b]{2}{*}{ Cheddar } & \multirow[b]{2}{*}{ Parmesano } & \multicolumn{2}{|c|}{ a $21^{\circ} \mathrm{C}$} & \multicolumn{2}{|c|}{ a $38^{\circ} \mathrm{C}$} & \multicolumn{2}{|c|}{ a $21^{\circ} \mathrm{C}$} & \multicolumn{2}{|c|}{ a $38^{\circ} \mathrm{C}$} \\
\hline & & & Cheddar & Parmesano & Cheddar & Parmesano & Cheddar & Parmesano & Cheddar & Parmesano \\
\hline$\alpha-\mathrm{CE}$ & 1.5 & 2.0 & 2.0 & 3.0 & 2.5 & 5.0 & 5.0 & 7.0 & 9.0 & 10.0 \\
\hline$\beta-\mathrm{CE}$ & 2.0 & 2.0 & 1.5 & ND & 1.5 & ND & 1.0 & ND & 2.5 & ND \\
\hline $7 \alpha-\mathrm{HC}$ & $\mathrm{ND}^{\circ}$ & ND & ND & ND & ND & ND & ND & ND & ND & ND \\
\hline $7 \beta-\mathrm{HC}$ & 8.5 & ND & 7.5 & ND & 6.0 & ND & 3.0 & ND & 3.0 & ND \\
\hline $25-\mathrm{HC}$ & ND & 2.0 & ND & 6.0 & ND & 5.0 & ND & 5.0 & ND & $4.0^{\circ}$ \\
\hline CT & ND & ND & ND - & ND & ND & ND & ND & ND & ND & ND \\
\hline $7-\mathrm{CC}$ & 1.5 & 3.0 & 2.5 & 4.0 & 1.5 & 12.0 & 2.0 & 5.0 & 2.5 & 3.0 \\
\hline Total & 13.5 & 9.0 & 13.5 & 13.0 & 11.5 & 22.0 & 11.0 & 17.0 & 17.0 & 17.0 \\
\hline
\end{tabular}

a No detectado.

TablaIV-Formación de $O E$ (ppm sobre lípidos) en productos en polvo obtenidos por atomización con fuente de calor indirecta (refs. 48 y 49).

\begin{tabular}{|l|c|c|c|c|c|c|c|}
\cline { 2 - 8 } \multicolumn{1}{c|}{} & \multicolumn{3}{c|}{ Yema de huevo en polvo } & \multicolumn{3}{c|}{ Leche en polvo b } \\
\cline { 2 - 8 } & Inicial & 2 meses & 6 meses & 12 meses & 13 meses & 30 meses & 36 meses \\
\hline$\alpha-\mathrm{CE}$ & $\mathrm{TR}^{\mathrm{c}}$ & $\mathrm{ND}$ & 1.3 & 2.5 & 1.8 & 2.0 & 2.7 \\
\hline$\beta-\mathrm{CE}$ & $\mathrm{ND}$ & $\mathrm{ND}$ & 6.5 & 12.0 & 0.7 & 5.7 & 8.1 \\
\hline $7 \alpha-\mathrm{HC}$ & $\mathrm{TR}$ & $\mathrm{TR}$ & 2.2 & 8.9 & 4.5 & 11.5 & 12.4 \\
\hline $7 \beta-\mathrm{HC}$ & $\mathrm{TR}$ & $\mathrm{TR}$ & 2.5 & 9.4 & 6.6 & 17.8 & 16.2 \\
\hline $25-\mathrm{HC}$ & $\mathrm{ND}$ & $\mathrm{ND}$ & $\mathrm{ND}$ & $\mathrm{ND}$ & 0.3 & 0.6 & 0.6 \\
\hline $\mathrm{CT}$ & $\mathrm{ND}$ & $\mathrm{ND}$ & $\mathrm{ND}$ & $\mathrm{TR}$ & $\mathrm{ND}$ & $\mathrm{ND}$ & 1.9 \\
\hline $7-\mathrm{CC}$ & $\mathrm{ND}$ & $\mathrm{TR}$ & 3.5 & 2.9 & 5.0 & 12.6 & 10.6 \\
\hline Total & $\mathrm{N}$ & - & 16.0 & 35.7 & 18.9 & 50.2 & 52.5 \\
\hline
\end{tabular}

a Almacenado a $4^{\circ} \mathrm{C}$.

b Almacenado a temperatura ambiente.

c Trazas.

d No detectado.

\subsection{Acción de las radiaciones.}

Como ya se ha dicho, a principios de siglo, SCHULZE Y WINTERSTEIN (66) observaron que el colesterol, en su forma cristalina, sufría una descomposición cuando era fuertemente irradiado con luz solar en presencia de aire, hecho que también fue adver- tido más tarde, en 1941, por BERGSTRÖM y WINTERSTEINER (6).

Posteriormente, se comprobó que la irradiación del colesterol en este mismo estado, a temperatura ambiente y con luz ultravioleta, conducía a la formación de los siguientes compuestos: $7 \alpha-\mathrm{HC}, 7 \mathrm{~B}-\mathrm{HC}, 7$ - 
CC, colest-1,4-dien-3-ona y 5-colestano (25).

Sobre este punto CHICOYE y cols., en 1968 (20), sugirieron que la oxidación fotoquímica experimentaba una disminución con el aumento de la longitud de onda, en las regiones ultravioleta, visible e infrarroja del espectro electromagnético.

Tabla V-Contenido de $O E$ (ppm) en una fórmula en polvo, $a$ base de huevo, obtenida por atomización con fuente de calor directa (FCD) o indirecta (FCI) (ref. 44).

\begin{tabular}{|l|c|c|}
\cline { 2 - 3 } \multicolumn{1}{c|}{} & \multicolumn{2}{c|}{ Atomización } \\
\cline { 2 - 3 } \multicolumn{1}{c|}{} & FCD & FCI \\
\hline$\alpha-\mathrm{CE}$ & 50.0 & 21.5 \\
\hline$\beta-\mathrm{CE}$ & 37.4 & 1.9 \\
\hline $7 \alpha-\mathrm{HC}$ & 7.0 & 1.8 \\
\hline $7 \beta-\mathrm{HC}$ & 18.5 & 1.5 \\
\hline $25-\mathrm{HC}$ & 5.1 & 1.4 \\
\hline $\mathrm{CT}$ & 13.0 & 11.6 \\
\hline $7-\mathrm{CC}$ & 37.0 & 2.0 \\
\hline Total & 168.0 & 41.7 \\
\hline
\end{tabular}

Fue a finales de los años 60 cuando se empezaron a estudiar los efectos de las radiaciones sobre el colesterol contenido en alimentos. Concretamente, uno de los primeros estudios de los que se tiene referencia es el realizado por CHICOYE y cols. (19). Este equipo de investigadores realizaron un tratamiento sobre yema de huevo en polvo con radiaciones no ionizantes, consiguiendo de esta forma identificar, tras la exposición, varios productos de fotooxidación del colesterol. Con posterioridad, se pudo demostrar que la exposición de yema de huevo en polvo, durante 12 días a luz fluorescente o 5 horas a luz solar intensa, daba lugar mayoritariamente a los productos de fotooxidación siguientes: $\alpha-\mathrm{CE}, 7 \alpha-\mathrm{HC}, 7 \mathrm{H}-\mathrm{HC}, \mathrm{CT}$ y $7-\mathrm{CC}$ (31).

Trabajos recientes han estudiado el efecto de la irradiación de ovoproductos y derivados lácteos con luz fluorescente, comprobándose que este tratamiento conduce a la formación de: $\alpha-C E, B-C E, 7 \alpha-H C$, 7 B-HC y 7-CC (31) (65).

\subsection{Tiempo y condiciones de almacenaje.}

El período de almacenaje y las condiciones en que éste se realiza influyen de forma clara en la formación de OE en alimentos (24) (44) (46) (48) (49) (65) (78). Entre los factores que inciden en la misma, se citan los siguientes: Temperatura (48) (65), radiaciones (65), humedad del producto (48), presencia de sustancias prooxidantes y antioxidantes (46), ventajas del envasado en atmósfera inerte (44) o al vacío (48), tamaño del envase (48) y naturaleza del mismo (24).

\subsection{Prevención de la autooxidación: Adición de} sal y antioxidantes.

Como es sabido, la oxidación lipídica en los alimentos es un proceso dependiente, entre otros, del factor actividad.del agua $\left(a_{w}\right)(40)$. La importancia del mismo, en relación con la formación de $O E$, ha sido estudiada por algunos autores.

En este sentido, SANDER y cols. (65) estudian, sobre un producto derivado de la mantequilla, el efecto de la adición de diferentes concentraciones de sal, comprobando que esta adición juega un importante papel en la prevención de la autooxidación del colesterol. Para estos autores, una disminución en $a_{w}$ implica una menor movilidad de los metales de transición, hecho que provoca un declive en la reactividad y en el efecto prooxidante de los mismos.

Se ha observado que la presencia de antioxidantes (glutation, galato de propilo, BHA y BHT) o bien de mezclas sinérgicas de ellos (palmitato de ascorbilo más dl- $\alpha$-tocoferol), evitan la formación de OE (46) (53) (55)

\subsection{Tratamientos tecnológicos.}

Como un ejemplo de las repercusiones de los tratamientos tecnológicos sobre la formación de $\mathrm{OE}$, podría citarse una cuestión relacionada con la elaboración de ovoproductos y tendente a prevenir el desarrollo de pardeamientos. Por esta razón, para ciertas aplicaciones, la yema de huevo en polvo debe estar exenta de glucosa. Esto se puede conseguir mediante un tratamiento enzimático, que consiste en añadir el sistema oxidasa-catalasa más agua oxigenada sobre yema de huevo líquida. Los enzimas se dejan actuar de 2.5 a 3 horas y después se procede al secado, generalmente por atomización, con el fin de obtener yema de huevo en polvo libre de glucosa. Este proceso puede incidir en la formación de $O E$, ya que se ha demostrado (69) que el peróxido de hidrógeno favorece la formación de epóxidos del colesterol $(\alpha-C E$ y $\beta-C E)$.

En vista de esto, MORGAN Y ARMSTRONG, en 1987 (46), estudiaron la formación de epoxicolesteroles (ECs) en yema de huevo en polvo, obtenida por atomización con fuente de calor indirecta, a partir de yema de huevo líquida, a la que se habían adicionado diferentes concentraciones de peróxido de hidrógeno. Se pudo observar que esta adición provocaba un aumento considerable del nivel de ECs en el producto así obtenido. Además, dicho nivel se disparaba de forma clara a lo largo del almacenaje de este producto, a causa de su contenido en $\mathrm{H}_{2} \mathrm{O}_{2}$ residual.

Se ha comprobado que el sistema de secado empleado en la obtención de productos deshidratados puede incidir en la formación de OE. En este sentido, el sistema más ventajoso para prevenir la formación 
de estos compuestos es la liofilización, ya que se ha observado que en ovoproductos, recién elaborados, desecados por este sistema, no se detectan niveles de OE (48) (77).

Por otro lado, en estudios realizados sobre la influencia del sistema de atomización en la formación de $\mathrm{OE}$, se ha comprobado que, si el aire que ejerce el efecto secante se calienta mediante una fuente de calor indirecta, la formación de $\mathrm{OE}$ es nula o poco significativa (44) (46) (49) (78), mientras que si este aire es calentado directamente a la llama de un mechero, la formación de OE es muy elevada (44) (78). Esto es debido, según diversos investigadores, a la presencia de óxidos de nitrógeno ( $\mathrm{NO}$ y $\mathrm{NO}_{2}$ ) en el aire calentado directamente. Estos compuestos se producen en la combustión del gas empleado en el mechero (44) (78). Respecto a este punto, MORGAN y ARMSTRONG en 1987 (46), realizaron una importante comprobación, al añadir $\mathrm{N}_{2} \mathrm{O}$ en el aire de un atomizador con fuente de calor indirecta. Este óxido a las altas temperaturas que se registran en el interior de atomizador, se descompone dando lugar a NO más $\mathrm{NO}_{2}$ Esto se traducía, directamente, en un aumento de la formación de $O E$ en los productos desecados. Sobre este punto, existen una serie de trabajos que evidencian que los óxidos de nitrógeno pueden actuar como iniciadores de la autooxidación del colesterol (67) (69) y de los ácidos grasos insaturados (60).

Otro sistema de secado estudiado es el que utiliza rodillos calientes. En este caso se ha observado que la formación de $O E$ es similar a la que tiene lugar cuando se usa la atomización con fuente de calor indirecta (49).

\subsection{Procesos de fritura.}

Como es sabido, las grasas utilizadas en procesos de fritura sufren un serie de cambios oxidativos, debidos al efecto combinado de las altas temperaturas y de la presencia de oxígeno. Esto ha sido citado, en relación con el colesterol, para los sebos empleados como medio de fritura (4) (51) (53) (55) (63) (64). En este sentido, diferentes autores han analizado la formación de oxiesteroles, sometiendo dichos productos a diferentes temperaturas, de las usualmente aplicadas en los procesos de fritura. Con ello se ha comprobado que, a temperaturas que oscilan entre $135^{\circ} \mathrm{C}-165^{\circ} \mathrm{C}$, la formación de ciertos $\mathrm{OE}$ es creciente con el tiempo de calefacción, mientras que por el contrario, a temperaturas superiores a $180^{\circ} \mathrm{C}$, los niveles de OE detectados, con diferentes períodos de calefacción, son muy bajos o bien nulos (51) (53). Esto es debido a que a medida que aumenta la temperatura se va acentuando cada vez más el predominio de la descomposición térmica del colesterol sobre su oxidación (51) (53). Estos trabajos tienen gran importancia, pues también han permitido con- cluir que los $O E$ formados durante el proceso de fritura pueden absorberse en los alimentos que se someten a dicho proceso. Así, RYAN (63) observa que el nivel de $O E$ presente en patatas fritas es cuatro veces superior al que se encuentra en su medio de fritura.

Otro de los productos usados con esta finalidad, aunque con menor frecuencia, es la mantequilla. Sobre este producto también se han efectuado estudios, para determinar como evolucionan sus niveles de $O E$, cuando es sometido a temperaturas elevadas. Uno de los más significativos es el realizado por SANDER y cols. (65), en el que se sometió un derivado de la mantequilla, durante 24 días, a un calentamiento continuo a $110^{\circ} \mathrm{C}$ y se analizaron los niveles de $\mathrm{OE}$ a lo largo de este período. Se observó un claro aumento, hasta el octavo dia, de los siguientes oxiesteroles: $\alpha-C E, B-$ $\mathrm{CE}, 7 \alpha-\mathrm{HC}, 7 \beta-\mathrm{HC}$ y $7-\mathrm{CC}$. A partir de este punto, aunque el 7-CC siguió aumentando, los otros cuatro $\mathrm{OE}$ disminuyeron o bien se estabilizaron. Durante este estudio se detectaron, además, bajas concentraciones de 25-HC y CT. Otro trabajo de gran importancia es el de CSIKY (22), que consistió en someter mantequilla a $180^{\circ} \mathrm{C}$ durante 5 minutos, con lo cual observó que la misma pasaba de contener solamente trazas de $25-\mathrm{HC}$, a presentar niveles apreciables de: $7 \alpha-H C, 7 B-H C, 25-H C, 7-C C$ y $4 B-H C$.

\section{DETERMINACION ANALITICA}

Los métodos descritos en la bibliografía consultada, para la determinación de los derivados oxidados del colesterol, parecen coincidir, a grandes rasgos, en el interés que supone la aplicación de la cromatografía de gases (CG) con columna capilar, como método de elección, para conseguir una buena resolución y cuantificación individualizada de los $\mathrm{OE}$ presentes en alimentos. Se utiliza con menor frecuencia la cromatografía líquida de alta eficacia (CLAE). Donde parece existir una mayor diversificación, con el fin de obtener una fracción que contenga de la forma más selectiva posible la globabilidad de productos de oxidación del colesterol, es en los procesos de extracción y purificación de la muestra. Por otra parte, siempre se trabaja evitando, en lo posible, las oxidaciones que puedan tener lugar durante el procedimiento analítico. Es por ello que, en la mayoría de las pautas analíticas revisadas, se observan unos cuidados especiales: las muestras son guardadas bajo unas condiciones controladas (44) (46) (48) (77) (78); las extracciones se realizan con la máxima rapidez, utilizando en algunos casos centrifugación (49) (52) (65); los disolventes se usan desgasificados (31) (44); se trabaja con luz difusa (49); y la evaporación de disolventes se realiza a presión reducida (31) (46) (47) (48) (49) (50) (64) (77) (78), bajo corriente de $N_{2}$ (46) (47) (48) (50) (52) (65) (77) o en rotavapor con atmósfera de $\mathrm{N}_{2}$ (44). 
Tabla VI-Procedimientos analiticos en la identificaciôn y/o determinación de $O E$.

\begin{tabular}{|c|c|c|c|}
\hline $\begin{array}{c}\text { Referencia } \\
\text { bibliográfica }\end{array}$ & Muestra & Patrones & $\begin{array}{l}\text { Extracción (E) y/o } \\
\text { saponificación (S) }\end{array}$ \\
\hline HERIAN y LEE, 1985 (31). & Huevo en polvo. & $7 \alpha-\mathrm{HC}, 7 \beta-\mathrm{HC}$ y colesterol. ${ }^{\circ}$ & $\begin{array}{l}\text { E: cloroformo/metanol }(2: 1, \mathrm{v} / \mathrm{v}) \text {. } \\
\mathrm{S}: \mathrm{KOH} / \text { etanol } 1.5 \mathrm{~N} \text { (en caliente). }\end{array}$ \\
\hline KORAHANI y cols., 1981 (42). & $\begin{array}{l}\text { Patrones por separado o como } \\
\text { mezclas y colesterol autooxidado } \\
\text { por calefacción. }\end{array}$ & 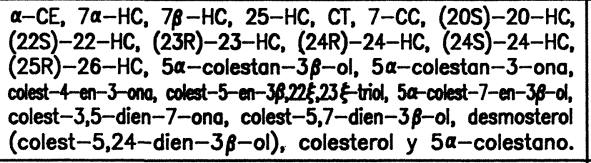 & \\
\hline MISSLER y cols., 1985 (44). & $\begin{array}{l}\text { Fórmula en polvo a base de } \\
\text { huevo. }\end{array}$ & $\begin{array}{l}\alpha-C E, \beta-C E, 7 \alpha-H C, 7 \beta-H C, 25-H C, C T, 7-C C, \\
(20 R)-20-H C \text { y } 6-C C . b\end{array}$ & E: cloroformo. \\
\hline $\begin{array}{l}\text { MORGAN y ARMSTRONG, } \\
1987(46) \text {. }\end{array}$ & Yema de huevo en polvo. & $\alpha$-CE. ${ }^{\circ}$ & E: cloroformo/metanol $(2: 1, v / v)$. \\
\hline $\begin{array}{l}\text { MORGAN y ARMSTRONG, } \\
1989 \text { (47). }\end{array}$ & $\begin{array}{l}\text { Estudio de las recuperaciones de } \\
\text { diferentes patrones en yema de } \\
\text { huevo en polvo. }\end{array}$ & 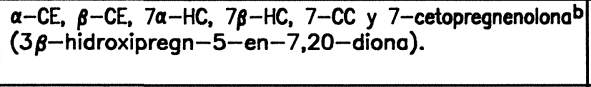 & E: cloroformo/metanol $(2: 1, v / v)$. \\
\hline $\begin{array}{l}\text { NOUROOZ-ZADEH Y } \\
\text { APPELQVIST, } 1987 \text { (48). }\end{array}$ & $\begin{array}{l}\text { Huevos frescos y ovoproductos en } \\
\text { polvo. }\end{array}$ & $\begin{array}{l}\alpha-C E, \beta-C E, 7 \alpha-H C, 7 \beta-H C, 25-H C, C T, 7-C C, \\
(20 R)-20-H C, \text { colesterol y } 5 \alpha \text {-colestano.b }\end{array}$ & E: hexano/isopropanol $(3: 2, v / v)$. \\
\hline $\begin{array}{l}\text { NOUROOZ-ZADEH y } \\
\text { APPELQVIST, } 1988 \text { (49). }\end{array}$ & Derivados lácteos en polvo. & 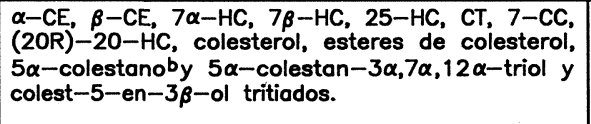 & E: hexano/isopropanol. \\
\hline PARK y ADDIS, 1985 (50). & $\begin{array}{l}\text { Patrones por separado o como } \\
\text { mezclas. }\end{array}$ & $\begin{array}{l}\alpha-\mathrm{CE}, 7 \alpha-\mathrm{HC}, 7 \beta-\mathrm{HC}, 25-\mathrm{HC}, \mathrm{CT}, 7-\mathrm{CC}, 4 \beta-\mathrm{HC}, \\
6-\text { cetocolestanol, colest-3,5-dien-7-ona, colesterol } \\
\text { y } 5 \alpha \text {-colestano.b }\end{array}$ & \\
\hline PARK y ADDIS, 1985 (52). & $\begin{array}{l}\text { Patatas fritas; pollo frito; concentrados } \\
\text { de cerebro e hígado; carne, hígado y } \\
\text { cerebro de buey; etc. }\end{array}$ & 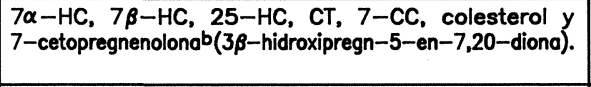 & E: cloroformo/metanol $(2: 1, v / v)$. \\
\hline PARK y ADDIS, 1986 (53). & Sebo colentodo a diferentes temperoturos. & $\alpha-C E, 7-C C$ y $5 \alpha$-colestano. ${ }^{b}$ & S: $\mathrm{KOH} /$ metanol $1 \mathrm{~N}$ (en frío). \\
\hline SANDER y cols., 1989 (65). & Derivados lácteos en polvo. & $\begin{array}{l}\alpha-C E, \beta-C E, 7 \alpha-H C, 7 \beta-H C, 25-H C, C T, 7-C C, \\
\text { colesterol y } 5 \alpha-\text { colestano. }^{b}\end{array}$ & $\begin{array}{l}\text { E: cloroformo/metanol }(2: 1, \mathrm{v} / \mathrm{v}) \text {. } \\
\mathrm{S}: \mathrm{KOH} / \mathrm{metanol} 1 \mathrm{~N} \text { (en frío). }\end{array}$ \\
\hline TENG y cols., 1973 (74). & Patrones. & $\begin{array}{l}7 \alpha-H C, 7 \beta-H C, 7-C C, 5 \alpha \text {-colest-6-en-3 } \beta, 5 \text {-diol, } \\
\text { colest-3,5-dien-7-ona, colest-4,6-dien-3-ona, } \\
\text { colest-2,4,6-trieno, colesterol, } \Delta^{6}-5 \alpha \text {-hidroperóxido, } \\
7 \alpha \text {-hidroperóxido y } 7 \beta \text {-hidroperóxido. } \\
\end{array}$ & \\
\hline TSAI y HUDSON, 1981 (76). & $\begin{array}{l}\text { Patrones por separado o como } \\
\text { mezclas. }\end{array}$ & 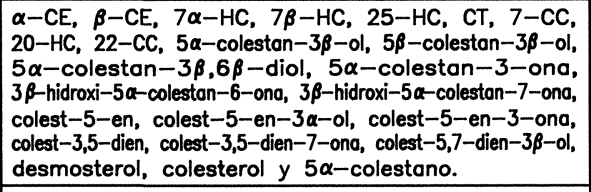 & \\
\hline TSAI y HUDSON, 1984 (77). & Ovoproductos en polvo. & $\alpha-C E, \beta-C E$ y $\alpha-C E$ tritiado. & E: acetona. \\
\hline TSAI y HUDSON, 1985 (78). & Ovoproductos en polvo. & $\alpha-C E$ y $\beta-C E$. & E: cloroformo/metanol $(2: 1, \mathrm{v} / \mathrm{v})$. \\
\hline
\end{tabular}


Tabla ł'T-Procedimientos analiticos en la identificaciôn y/o determinaciôn de OE (continuaciôn).

\begin{tabular}{|c|c|c|c|}
\hline $\begin{array}{c}\text { Referencia } \\
\text { bibliográfica }\end{array}$ & Purificación o fraccionamiento & Identificación $\mathrm{y} / \mathrm{o}$ determinaciôn & $\begin{array}{c}\text { Compuestos identificados } \\
\text { y/o cuantificados }\end{array}$ \\
\hline $\begin{array}{l}\text { HERIAN y LEE, } 1985 \\
\text { (31). }\end{array}$ & $\begin{array}{l}\text { n) Columna secuestrante + columna con } \\
\text { impregnación argéntica. }\end{array}$ & \begin{tabular}{|l|}
$n-1)$ CCF con gel de sílice 60. \\
n) CLAE con columna de LiChrosorb Si 60 y foses \\
móviles: hexano/isopropanol $(100: 3$, v/v y $11: 1$, v/v).
\end{tabular} & $7 \alpha-H C$ y $7 \beta-H C$. \\
\hline $\begin{array}{l}\text { KORAHANI y cols., } \\
\text { I981 (42). }\end{array}$ & n) CCF preparativa con gel de sílice $60 \mathrm{~F}_{254}$ & 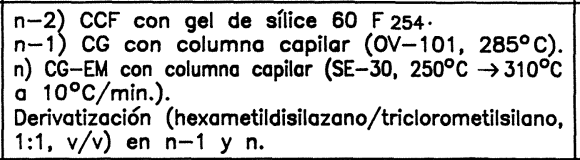 & $\begin{array}{l}\text { Patrones; y en colesterol autooxidado: } \\
\alpha-\mathrm{CE}, 7 \alpha-\mathrm{HC}, 7 \beta-\mathrm{HC}, 25-\mathrm{HC}, 7-\mathrm{CC}, \\
\text { (20S)-20-HC y colest-3,5-dien-7-ono. }\end{array}$ \\
\hline $\begin{array}{l}\text { MISSLER y cols., } \\
1985(44) .\end{array}$ & $\begin{array}{l}\text { n) columna de gel de silice LC + CLAE preparativa } \\
\text { con columna de gel de silice. }\end{array}$ & $\begin{array}{l}\text { n-1) CG con columna capilar (DB-1, } 70^{\circ} \mathrm{C} \rightarrow 270^{\circ} \mathrm{C} \mathrm{a} \\
25^{\circ} \mathrm{C} / \min . \text { y } 270^{\circ} \mathrm{C} \longrightarrow 300^{\circ} \mathrm{C} \text { a } 1{ }^{\circ} \mathrm{C} / \mathrm{min} \text {.). } \\
n \text { ) CG-EM. } \\
\text { Derivatización (BSTFA) en } n-1 \text { y } n \text {. }\end{array}$ & $\begin{array}{l}\alpha-C E, \beta-C E, 7 \alpha-H C, 7 \beta-H C, 25-H C, \\
\text { CT y } 7-C C .\end{array}$ \\
\hline $\begin{array}{l}\text { MORGAN y ARMSTRONG, } \\
1987 \text { (46). }\end{array}$ & n) Cortucho de gel de sílice. & $\begin{array}{l}\text { n) } \mathrm{CG} \text { con columna de relleno }\left(3 \% \text { ov- } 17,240^{\circ} \mathrm{C} \rightarrow 280^{\circ} \mathrm{C}\right. \\
\text { a } 5^{\circ} \mathrm{C} / \mathrm{min} \text {.). Sin derivatización. }\end{array}$ & Epoxicolesteroles $(\alpha-\mathrm{CE}+\beta-\mathrm{CE})$. \\
\hline $\begin{array}{l}\text { MORGAN y ARMSTRONG, } \\
1989(47) \text {. }\end{array}$ & n) Cortucho de gel de sílice. & $\begin{array}{l}\text { n) CG con columna capilar (HP-17, } 225^{\circ} \mathrm{C} \rightarrow 275^{\circ} \mathrm{C} \\
\text { o } 1^{\circ} \mathrm{C} / \text { min.). Derivatización }(B S T F A) .\end{array}$ & $\begin{array}{l}\text { En yema de huevo en polvo: } 7 \alpha-H C \text {, } \\
7 \beta-H C \text { y } 7-C C \text {. Recuperaciones de: } \\
\alpha-C E, \beta-C E, 7 \alpha-H C, 7 \beta-H C \text { y } 7-C C \text {. }\end{array}$ \\
\hline $\begin{array}{l}\text { NOUROOZ-ZADEH Y } \\
\text { APPELQVIST, } 1987 \\
\text { (48). }\end{array}$ & \begin{tabular}{|l|} 
n) Gel filtración con columna de Lipidex $5000+$ \\
intercambio ónnico con columna de TEAP Lipidex + \\
soponificación con KOH/etonol $2 \mathrm{~N}$ (en caliente).
\end{tabular} & \begin{tabular}{|l|}
$n-2)$ CCF con gel de sílice $60 \mathrm{~F} 254$. \\
$n-1)$ CG con columno copilar (metil-silicono, $\left.280^{\circ} \mathrm{C}\right)$. \\
$n$ ) CG-EM con columna copilar (metil-silicona, 260 20 ). \\
Derivatización (Tri-Sil) en $n-1$ y $n$.
\end{tabular} & $\begin{array}{l}\alpha-C E, \beta-C E, 7 \alpha-H C, 7 \beta-H C, 25-H C, \\
C T, 7-C C \text { y }(20 R)-20-H C .\end{array}$ \\
\hline $\begin{array}{l}\text { NOUROOZ-ZADEH Y } \\
\text { APPELQVIST, } 1988 \\
\text { (49). }\end{array}$ & $\begin{array}{l}\text { n-1) CCF preporativa con gel de sílice } 60 \text { para } \\
\text { separar el colesterol libre de sus esteres. } \\
\text { n) Cartucho de gel de sílice + gel filtroción con } \\
\text { columno de Lipidex } 5000+\text { intercombio iónico con } \\
\text { columno de TEAP Lipidex + soponificoción } \\
\text { con KOH/etanol } 2 \mathrm{~N} \text { (en caliente). }\end{array}$ & $\begin{array}{l}n-2) \text { CCF con gel de sílice } 60 \text { F } 254 . \\
n-1) \text { CG con columna copilar (metil-silicona, } 270^{\circ} \mathrm{C} \text { ). } \\
n \text { n) CG-EM.c } \\
\text { Derivatización (Tri-Sil) en } n-1 \text { y } n .\end{array}$ & $\begin{array}{l}\alpha-C E, \beta-C E, 7 \alpha-H C, 7 \beta-H C, 25-H C, \\
C T, 7-C C,(20 R)-20-H C \text {, colesterol } \\
\text { libre y esterificado. }\end{array}$ \\
\hline $\begin{array}{l}\text { PARK y ADDIS, } 1985 \\
\text { (50). }\end{array}$ & & 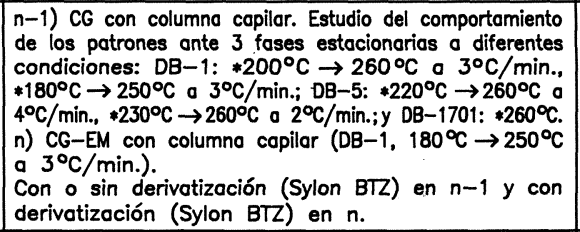 & Patrones. \\
\hline $\begin{array}{l}\text { PARK y ADDIS, } 1985 \\
\text { (52). }\end{array}$ & n) Columna de gel de sílice $\mathrm{H}$. & $\begin{array}{l}\text { n-1) CLAE con columno de } \mu \text { Porasil y fase movil: } \\
\text { hexano/isoproponol }(93: 7, v / v) \text {. } \\
\text { n) CG-EM. }\end{array}$ & $7 \alpha-\mathrm{HC}, 7 \beta-\mathrm{HC}$ y $7-\mathrm{CC}$ \\
\hline PARK y ADDIS, 1986 (53). & $=$ & n) CG con columno capilar (según ref. 50). & $\alpha-C E$ y $7-C C$. \\
\hline $\begin{array}{l}\text { SANDER y cols., } 1989 \\
\text { (65). }\end{array}$ & & $\begin{array}{l}n-1) \mathrm{CG} \text { con columno capilar }\left(\mathrm{DB}-1,180^{\circ} \mathrm{C} \rightarrow 250^{\circ} \mathrm{C}\right. \\
\text { a } 3{ }^{\circ} \mathrm{C} / \mathrm{min} . \text {.). } \\
n \text { ) CG-EE.c } \\
\text { Derivatización (Sylon BTZ) en } n-1 \text { y } n \text {. }\end{array}$ & $\begin{array}{l}\alpha-C E, \beta-C E, 7 \alpha-H C, 7 \beta-H C, 25-H C, \\
\text { CT y } 7-\mathrm{CC} .\end{array}$ \\
\hline $\begin{array}{l}\text { TENG y cols., } 1973 \\
\text { (74). }\end{array}$ & & \begin{tabular}{|l|}
$n-1)$ CCF con gel de sílice HF 254 \\
$n)$ CG con columnas de relleno $(2 \%$ y $3 \%$ ov-210 y \\
$2 \%$ y $3 \%$ SP-2401, en los 4 cosos o $230^{\circ}$ C).
\end{tabular} & \begin{tabular}{|l} 
Potrones. \\
\end{tabular} \\
\hline $\begin{array}{l}\text { TSAl y HUDSON, } 1981 \\
\text { (76). }\end{array}$ & & $\begin{array}{l}\text { n) CLAE con columna de } \mu \text { Porasil y foses móviles: } \\
\text { hexano/isopropanol (diferentes proporciones, } v / v \text { ), hexano/ } \\
\text { ocetoto de etilo (diferentes proporciones, } v / v \text { ) y hexano/ } \\
\text { tetrahidrofurano (diferentes proporciones, } v / v \text { ). }\end{array}$ & Patrones. \\
\hline $\begin{array}{l}\text { TSAl y HUDSON, } 1984 \\
\text { (77). }\end{array}$ & n) Columna de Bio-Sil HA. & $\begin{array}{l}\text { n-3) CLAE con columna de LiChrosorb Si } 60 \text { y } \\
\text { fose móvil: hexano/isopropanol }(98: 2, v / v) \text {. } \\
n-2) \text { EM. } \\
n-1) \text { Espectroscopio infrarrojo. } \\
\text { n) Espectroscopia de resonancio magnética nuclear. }\end{array}$ & $\alpha-$ CE y $\beta$-CE. \\
\hline $\begin{array}{l}\text { TSAl y HUDSON, } 1985 \\
\text { (78). }\end{array}$ & n) Cartucho de gel de sílice. & $\begin{array}{l}n-1) \text { CG con columna de relleno (3\% OV-17. } \\
225^{\circ} \mathrm{C} \rightarrow 265^{\circ} \mathrm{C} \text { a } 4^{\circ} \mathrm{C} / \mathrm{min} \text {.). } \\
n) \mathrm{CLE} \text { con columna de } \mu \text { Porasil y fase móvil: } \\
\text { hexano/isopropanol }(100: 3 \text {, v/v). }\end{array}$ & $\alpha-$ CE y $\beta$-CE. \\
\hline
\end{tabular}

c CG con columna y condiciones, idénticas a las de $n-1$. 
Los procedimientos analíticos más significativos, de los que hemos revisado, se encuentran resumidos en la tabla VI. No obstante, es del todo necesario realizar un breve comentario sobre una serie de puntos de interés, ya que algunos son objeto de discrepancia entre diversos autores. Los puntos a tratar se engloban en tres apartados: extracción y obtención de la fracción insaponificable, purificación y determinación.

\subsection{Extracción y obtención de la fracción insa- ponificable.}

Los OE se encuentran en la fracción lipídica de los productos alimenticios formando parte de su porción insaponificable. Por ello, en ocasiones, tras la extracción de los lípidos de estos productos con disolventes adecuados, tales como cloroformo/metanol $(2: 1, \mathrm{v} / \mathrm{v})$ (31) (46) (47) (52) (65) (79) (78), cloroformo (44), hexano/isopropanol (48) (49) y acetona (77), se realiza una saponificación del extracto graso obtenido y la subsiguiente extracción del insaponificable con éter etílico (31) (43) (65). Esta saponificación es una etapa especialmente importante y controvertida, ya que puede ser el origen de artefactos. Así, MAERKER y UNRUH (43) observaron la formación de OE al someter colesterol puro en un sustrato de trioleína a saponificación en medio alcalino $y$ en caliente, por dos métodos diferentes. En este mismo trabajo estos dos autores demostraron que tanto los epoxicolesteroles ( $\alpha$-CE y $B-C E)$, como los 7-hidroxicolesteroles ( $7 \alpha-H C$ y $7 B-$ $H C)$, son estables a las condiciones de saponificación que emplean estos dos métodos, mientras que el 7 $\mathrm{CC}$ es destruido en estas mismas condiciones. Esta última observación se halla respaldada por una serie de trabajos (20) (51), en los que se demuestra que el 7-CC da lugar como artefacto a colest-3,5-dien-7ona, producto de la saponificación a altas temperaturas en medio alcalino. En cambio, otros autores (48) defienden la utilización de este método, ya que con ello, junto a los OE sin esterificar, se consiguen determinar también los $O E$ esterificados. En la bibliografía más reciente (53) (65) se observa que la tendencia preferente es la de saponificar en frío.

\subsection{Purificación.}

La purificación del extracto, como puede observarse en la tabla VI, se realiza mediante métodos diversos, entre los cuales, la cromatografía en capa fina preparativa parece sufrir una regresión en su aplicación, siendo el trabajo más reciente que la utiliza, entre los revisados, el realizado en 1981 por KORAHANI y cols. (42). No obstante, esta técnica cromatográfica ha sido posteriormente usada, en 1988, por NOUROOZ-ZADEH y APPELQVIST (49), pero en este caso únicamente para separar el colesterol libre de sus ésteres. Este método ha sido reemplazado por otros procedimientos, de los cuales el más simple y más frecuentemente utilizado en la actualidad es el cartucho de gel de sílice (46) (47) (49) (78) (79).

Los eluyentes empleados son de una importancia trascendental de cara a la ausencia de interferencias en la determinación. Las interferencias a eliminar son básicamente: fosfolípidos, glicéridos, ácidos grasos libres (AGL) y colesterol. En esta eliminación también juega un papel importante el disolvente utilizado durante la extracción. Así por ejemplo, según TSAI y HUDSON (77), cuando se trabaja con huevos es interesante realizar la extracción con acetona, ya que este disolvente excluye los fosfolípidos, que constituyen aproximadamente un $27 \%$ de los lípidos del huevo. En ocasiones, la purificación se realiza de tal forma que permita dividir el conjunto de $O E$ contenido en un producto alimenticio en varias fracciones. La finalidad de esta operación es la de evitar que estos compuestos se interfieran entre sí durante la determinación (42) (48) (49)

\subsection{Determinación.}

El método mas usual en la determinación de $\mathrm{OE}$ es la CG (42) (44) (46) (47) (48) (49) (50) (53) (64) (65) (74) (78) (79) que permite evaluar, cuali y cuantitativamente, el contenido de OE. No obstante, normalmente la identificación debe confirmarse aplicando la CG asociada a la espectroscopia de masas (EM) (42) (44) (48) (50) (65). Para realizar la cuantificación mediante CG, en la mayoría de los casos, se utiliza el método del patrón interno (44) (47) (48) (49) (50) (53) (65), pero en cambio, MORGAN $Y$ ARMSTRONG (46) hacen uso de un patrón externo. En general se realiza una silanización previa a la CG, aunque no siempre es así (46) (50) (74). En un trabajo de PARK Y ADDIS (50), se observa que los tiempos de retención de los derivados silanizados proveen una mejor resolución, independientemente de las columnas utilizadas. Además, en este mismo trabajo se advierte que esta derivatización evita la descomposición térmica de los OE durante la CG. Para este tratamiento los reactivos silanizantes más frecuentemente utilizados son los que siguen: Sylon BTZ (50) (53) (65), Tri-Sil (48) (49) y BSTFA (44) (47). Estos tres reactivos actúan formando trimetilsilil-éteres (TMSéteres) sobre los grupos hidroxilo de los diferentes $\mathrm{OE}$. De los tres, el más potente es el Sylon BTZ, capaz de formar TMS-éteres con todos los grupos hidroxilo de una molécula, sea cual sea su posición. En cambio, los otros dos reactivos no consiguen más que una silanización parcial, ya que no actúan sobre los hidróxilos que se encuentran en determinadas posiciones. Este hecho influye en el tiempo de retención y, por lo tanto, en la resolución. Así, en un trabajo de MISSLER y cols. (44) se observa que, para la columna usada en este caso, el empleo de BSTFA implica una mejor resolución, que la utilización de reactivos que conduzcan a derivados completamente silanizados. 
Otro método utilizado en la determinación, con fines cuali y cuantitativos, es la CLAE (31) (52) (76) (77) (78) (79). El análisis cualitativo también viene, en ocasiones, confirmado por CG-EM (52) o EM (77) e incluso por espectroscopia de resonancia magnética nuclear y por espectroscopia infrarroja (77). La evaluación cuantitativa, en este caso, también se realiza por el método del patrón interno (52) o por el del patrón externo (31). Esta técnica cromatográfica era preconizada por algunos autores como la única capaz de resolver con eficacia la mezcla de colesterol-5,6-epóxidos (46) (76) (78) (79). Pero a partir del año 1985 , se encuentran diversos trabajos que separan bien estos compuestos mediante CG con columna capilar (44) (47) (48) (49) (65), de tal forma que, actualmente, este es el método de elección para el análisis de mezclas complejas de $O E$, como las que pueden presentarse en los productos alimenticios. La introducción de este método ha supuesto un retroceso en el uso de la CG con columnas de relleno, ya que estas columnas deparan una resolución insuficiente, pues son incapaces de separar los colesterol5,6-epóxidos ( $\alpha$-CE y $B$-CE) e incluso, en ciertos casos, los 7-hidroxicolesteroles $(7 \alpha-\mathrm{HC}$ y $7 \beta-\mathrm{HC})$.

\section{AGRADECIMIENTO}

La realización de esta revisión bibliográfica ha sido posible, en parte, gracias a la beca de formación de investigadores concedida a $D$. Francisco Guardiola Ibarz por el Departament d'Ensenyament de la Generalitat de Catalunya. Asímismo, agradecemos la cesión desinteresada, por parte de la sociedad cooperativa CODEBAGES, del programa AUTOCAD 9.3 con el cual hemos realizado las tablas $y$ esquemas de este trabajo. Por último, queremos expresar nuestro agradecimiento a la Srta. M. ${ }^{\text {a }}$ del Carmen Sala Villaplana por su inestimable colaboración.

\section{BIBLIOGRAFIA}

1. Acker, L. y Greve, H.- "Uber die Photoxydation des Cholesterins in Eihaltigen Lebensmitteln".- Fette Seif. Anstrich. 65 (1963) 1009.

2. Addis, P. B.-"Ocurrence of lipid oxidation products in foods".Food Chem. Tox. 24 (1986) 1021.

3. Ansari, G. A. S., Walke, R. D., Smart V .B. y Smith, L. L."Further investigations of mutagenic cholesterol preparations".Food. Chem. Tox. 20 (1982) 35

4. Bascoul, J., Domerge, N. y Crates de Paulet, A.- "Intestinal absorption of cholesterol autoxidation products in dietary fats". J. Am. Oil Chemists' Soc. 62 (1985) 623.

5. Bates, S. R., Jett, C. M., y Miller, J. E.- "Prevention of the hyperlipidemic serum or LDL-induced cellular cholesterol ester accumulation by 22-hydroxycholesterol and its analogue".Biochim. Biophys. Acta 753 (1983) 281.
6. Bergström, S. y Wintersteiner, O.- "Autoxydation of sterols in coloidal aqueous solutions".- J. Biol. Chem. 141 (1941) 597.

7. Bergström, S. y Wintersteiner, O.- "Autoxydation of sterols in coloidal aqueous solutions III: Quantitative studies on cholesterol".- J. Biol. Chem. 145 (1942a) 309.

8. Bergström, S. y Wintersteiner, O.- "Autoxydation of sterols in coloidal aqueous solutions IV: Influence of esterification and of constitutional factors".- J. Biol. Chem. 145 (1942b) 327.

9. Bischoff, F.- "Carcinogenic effect of steroids" En Advances in lipid research.- R. Paoletti y D. Kritchevsky (ed.).- Academic Press, New York, p. 165, 1969.

10. Black, H. S. y Chan, J. T.- "Etiologic related studies of ultraviolet light-mediated carcinogenesis".- Oncology 33(1976) 119

11. Black, H. S. y Douglas, D. R.- "Model system for the evaluation of the role of cholesterol $\alpha$-oxide in ultraviolet carcinogenesis".Cancer Res. 32 (1972) 2630

12. Black, H. S. y Lo, W. B.- "Formation of a carcinogen in human skin irradiated with ultraviolet light".- Nature 234 (1971) 306.

13. Blackburn, G. M., Rashid, A. y Thompson, M. H.- "Interaction of $5 \alpha, 6 \alpha$-cholesterol oxide with DNA and other nucleophiles" J. Chem. Soc. Chem. Commun. p. 420, 1979.

14. Brown, M. S. y Goldstein, J. L.- "Supression of 3-hidroxy-3methylglutaryl coenzyme $A$ reductase activity and inhibition of growth of human fibroblasts by 7-ketocholesterol".- J. Biol Chem. 249 (1974) 7306

15. Cavenee, W. K., Chen, H. W. y Kandutsch, A. A.- "Regulation of cholesterol biosynthesis in enucleated cells".- J. Biol. Chem. 256 (1981) 2675

16. Chan, J. T. y Black, H. S.- "Skin carcinogenesis: Choresterol$5 \alpha$, $6 \alpha$-epoxide hydrase activity in mouse skin irradiated with ultraviolet light".- Science 186 (1974) 1216.

17. Chen H. W., Kandutsch, A. A. y Waymouth, C.- "Intribition of cell growth by oxygenated derivatives of cholesterol".- Nature 251 (1974) 419

18. Chen, H. W., Richards, B. A. y Kandutsch, A. A.- "Inhibition of protein synthesis blocks the response to 25-hydroxycholesterol by inhibiting degradation of hydroxymethylglutaryl- CoA reductase".- Biochim. Biophys. Acta 712 (1982) 484.

19. Chicoye, E., Powrie, W. D. y Fennema, O.- "Photoxidation of cholesterol in spray-dried egg yolk upon irradiation".- J. Food Sci. 3 (1968a) 581

20. Chicoye, E., Powrie, W. D. y Fennema, O.- "Isolation and characterization of cholesterol- $5 B, 6 \beta$-oxide from an aerated aequeous dispersion of cholesterol".- Lipids 3 (1968b) 335

21. Crastes de Paulet, A., Astruc, M. E. y Bascoul, J.- "Les oxystérols: Propriétés biologiques et problemes nutritionnels". En "Biologie des lipides chez I'homme".- Editions Médicales Internationales.- Paris, p. 154, 1988

22. Csiky, 1.- "Trace enrichment and separation of cholesterol oxidation products by absorption high perfomance liquid chromatography".- J. Chromatogr. 24 (1982) 381.

23. Danielson, H. y Horning, M. G.- "On the oxidation of cholesterol by blood in vitro".- Acta Chem. Scand. 16 (1962) 774.

24. Finochiaro, E. T., Lee, K. y Richarson, T.- "Identification and quantification of cholesterol oxides in grated cheese and bleached butteroil".- J. Am. Oil Chemists' Soc. 61 (1984) 877.

25. Fioriti, J. A. y Sims, R. J.- "Autoxidation products of cholesterol".- J. Am. Oil Chemists' Soc. 44 (1967) 221.

26. Florez, J., Armijo, A. J. y Mediavilla, A.- "Farmacologia humana".- EUNUSA. - Pamplona, vol. II, p. 676, 1987.

27. Folch, J., Lees, M., y Sloane-Stanley, G. H.- "A simple method for the isolation and purification of total lipids from animal tissues".- J. Biol. Chem. 226 (1957) 477.

28. Gilbert, J. D., Brooks, C. J. W. y Harland, W. A.- "Lipids of human atheroma. VII. Isolation of diesters of cholest-5-ene-3B,26diol from extracts of advanced atherosclerotic lesions of human aortan.- Biochim. Biophys. Acta 270 (1972) 149. 
29. Gray, M. F., Lawrie, T.D.V.y Brooks, C.J.W.- "Isolation and identification of cholesterol $\alpha$-oxide and other minor sterols in human serum".- Lipids 6 (1971) 836.

30. Harper, H. A., Rodwell, V. W. y Mayes P. A.- "Manual de química fisiológica. Manual moderno".- Méjico, p. 918, 1980.

31. Herian, A. M. y Lee, K.- "7 $\alpha$-and $7 ß$-hydroxycholesterols formed in a dry egg nog mix exposed to fluorescent light".- J. Food. Sci. 50 (1985) 276 .

32. Herrera, E.- "Bioquimica".- Interamericana.- Madrid, p. 954, 1986.

33. Imai, H., Werthessen, N. T., Subramanyam, V., LeQuesne, $P$ W., Soloway, A. H. y Kanisawa, M.- "Angiotoxicity of oxygenated sterols and possible precursors".- Science 207 (1980) 651

34. Imai, H., Werthessen, N. T., Tailor, C. B. y Lee, K. T.- "Angiotoxicity and arteriosclerosis due to contaminats of USP-grade cholesterol".- Arch. Pathol. Lab. Med. 100 (1976) 565.

35. Jungermann, K., y Möhler, H.- "Bioquimica".- Pirámide.- Madrid, p. 602,1984

36. Kadis, B.- "Steroid epoxides in biological systems: A review".J. Steroid Biochem. 9 (1978) 75.

37. Kandutsch, A. A. y Chen, H. W.- "Inhibition of sterol synthesis in cultured mouse cells by $7 \alpha$-hydroxycholesterol, $7 \beta$-hydroxycholesterol and 7-Ketocholesterol".- J. Biol. Chem 248 (1973) 8408 .

38. Kandustch, A. A. y Chen, H. W.- "Inhibition of cholesterol synthesis by oxygenated sterols".- Lipids 13 (1978) 704.

39. Kandutsch, A.A., Chen, H.W. y Heiniger, H. J.- "Biological activity of some oxygenated sterols".- Science 201 (1978) 498.

40. Karel, M.- "Lipid oxidation secondary reactions and water activity of foods". En "Autoxidation in food and biological systems".M.G. Simic y M. Karel (Ed.)- Plenum Press, New York, p. 191, 1980.

41. Kelsey, M. I. y Pienta, R. J.- "Transformation of hamster embryo cells by cholesterol $\alpha$-epoxide and lithocholic acid".- Cancer Lett 6 (1979) 143.

42. Korahani, V., Bascoul, J. y Crastes de Paulet, A.- "Capillary column gas-liquid chromatographic analysis of cholesterol derivatives. Application to the autoxidation products of cholesterol".J. Chromatogr. 211 (1981) 392.

43. Maerker, G. y Unruh, J.- "Cholesterol oxides. 1. Isolation and determination of some cholesterol oxidation products"- J. Am. Oil Chemists' Soc. 63 (1986) 767.

44. Missler, S. R., Wasilchuk, B. A. y Merritt, C.- "Separation and identification of cholesterol oxidation products in dried egg preparations"-J. Food. Sci. 50 (1985) 595.

45. Mitropoulos, K. A. y Venkatesan, S.- "The influence of cholesterol on the activity, on the isothermic kinetics and on the temperature-induced kinetics of 3-hydroxy-3-methylglutaryl coenzyme A reductase".- Biochim. Biophys. Acta 489 (1977) 126.

46. Morgan, J. N. y Armstrong, D. J.- "Formation of cholesterol-5,6epoxides during Spray-drying of egg yolk".- J. Food Sci. 52 (1987) 1224.

47. Morgan, J. N. y Armstrong, D. J.- "Wide-bore capillary gas chromatographic methods for quantification of cholesterol oxidation products in egg yolk powder".- J. Food Sci. 54 (1989) 427.

48. Nourooz-Zadeh, J. y Appelqvist, L. A.- "Cholesterol oxides in swedish foods and food ingredients: Fresh eggs and dehydrated egg products".- J. Food Sci. 52 (1987) 57

49. Nourooz-Zadeh, J. y Appelquist, L-A.- "Cholesterol oxides in swedish foods and food ingredients: Milk powder products".- J. Food Sci. 53 (1988) 74.

50. Park, S. W. y Addis, P. B.- "Capillary column gas-liquid chromoatographic resolution of oxidized cholesterol derivatives".Anal. Biochem. 149 (1985a) 275.

51. Park, S. W. y Addis, P. B.- "Identification and quantitative estimation of oxidized cholesterol derivatives in heated tallow".J. Agric. Food Chem. 34 (1985b) 653.
52. Park, S. W. y Addis, P. B.- "HPLC determination of C-7 oxidized Cholesterol derivatives in foods".- J. Food Sci. 50 (1985c) 1437.

53. Park, S. W. y Addis, P. B.- "Further investigation of oxidized cholesterol derivatives in heated fats".- J. Food Sci. 51 (1986) 1380 .

54. Parson, P. G. y Goss, P.- "Chromosome damage and DNA repair synthesis induced in human fibroblasts by UV and Cholesterol oxide".- Aust. J. Exp. Biol. Med. Sci. 56 (1978) 287

55. Pearson, A. M., Gray, J. I., Wolzak, A. M. y Horenstein, N. A."Safety implications of oxidized lipids in muscle foods".- J. Food Tehnol. 37 (1983) 121.

56. Peng, S. K., Taylor, C. B., Hill, J. y Safarik, J.- "The effect of oxidized cholesterol on the aorta of rabbits: Scannig electron microscopic observations".- Proc. Annu. Meet., Electron Microsc. Soc. Am. 40th, 1982a

57. Peng, S. K., Taylor, C. B., Mosbach, E. H., Huang, W. Y., Hill, J. y Mikelson, B.- "Distribution of 25-hydroxycholesterol in plasma lipoproteins and its role in atherogenesis".- Artherosclerosis 41 (1982b) 395.

58. Peng, S. K., Tham, P., Taylor, C. B. y Mikelson, B.-"Cytotoxicity of oxidation derivatives of cholesterol on cultures aortic smooth muscle cells and their effect on cholesterol biosynthesis".- Am. J. Clin. Nutrition 32 (1979) 1033.

59. Philippot, J. R., Sainte-Marie, J. y Vermas, S.- "Changes in lipid organization and membrane function induced by low concentrations of 25-hydroxycholesterol". En "Activités biologiques des oxystérols".- J. P. Beck y A. Crastes de Paulet (Ed.).- Colloque INSERM 166 (1987) 151

60. Pryor, W.A. y Lightsey, J.W.- "Mechanisms of nitrogen dioxide reactions: Initiation of lipid peroxidation and the production of nitrous acid".- Science 48 (1981) 435.

61. Rawn, J. D.- "Bioquimica".- Interamericana- Mc Graw Hill.Madrid, vol. II, p. 564, 1989.

62. Richert, L., Bergmann, C., Beck, J. P., Rong, S., Luu, B. y Quirsson, G.- "The importance of the serum lipoprotein in the cytolytic action of 7 B-hydroxycholesterol on cultured hepatoma cells".- Biochem. Biophys. Res. Comm. 117 (1983) 851.

63. Ryan, T. C. 1982.- "Oxidation of cholesterol in heated tallow". En "Safety implications of oxidized lipids in muscle foods".- A.M Pearson, J.I. Gray, A. M. Wolzak y N.A. Horenstein.- J. Food Technol. 37 (1983) 121

64. Ryan, T. C., Gray, J. I. y Morton, I. D.- "Oxidation of cholesterol in heated tallow".- J. Sci. Food Agric. 32 (1981) 305

65. Sander, B. D., Smith, D.E., Addis, P. B. y Park, S. W.- "Effects of prolonged and adverse storage conditions on levels of cholesterol oxidation products in dairy products".- J. Food Sci. 54 (1989) 874

66. Schulze, E. y Winterstein, E. 1904.- "Uber das verhatten des Cholesterins gegen des Lict". En "Effects of prolonged and adverse storage conditions on levels of oxidation products in dairy products".- B.D. Sander, D. E. Smith, P. B. Addis y S. W. Park.- J. Food Sci. 54 (1989) 874

67. Sevanian, A., Mead, J. F. y Stein, R. A.- "Epoxides as products of lipid autoxidation in rat lungs".- Lipids 14 (1979) 634

68. Sevanian, A. y Peterson, A. R.- "Cholesterol epoxide is a direct acting mutagen".- Proc. Natl. Acad. Sci. USA 81 (1984) 4198.

69. Smith, L. L.- "Cholesterol autoxidation".- Plenum Press".- New York, 1981.

70. Smith, L. L. y Kulig, M. J.- "Sterol metabolism. XXXIV. On The derivation of carcinogenic sterols from cholesterol".- Cancer Biochem. Biophys 1 (1975) 79

71. Smith, L. L., Smart, V. B. y Ansari, G.A.S.- "Mutagenic cholesterol preparation".- Mutation Res. 68 (1979) 23.

72. Tanaka, R. D., Edwards, P. A., Lan, S-F. y Fogelman, A. M."Regulation of 3-hydroxy-3-methylglutaryl Coenzyme $A$ reductase Activity in avian myeloblasts".- J. Biol. Chem. 258 (1983) 13331. 
73. Taylor, F. R., Saucier, S. E., Shown, E, P., Parish, E. J. y Kandutsch, A.A.-"Correlation between oxysterol binding to a cytosolic binding protein and potency in the repression of hydroxymethylglutaril coenzime A reductase".- J. Biol. Chem. 259 (1984) 12382.

74. Teng, J. I., Kulig, M. J. y Smith, L. L.- "Sterol metabolism. XXII. Gas chromatographic differentiation among cholesterol hydroperoxides".- J. Chromatogr. 75 (1973) 108.

75. Teng, J. I., Kulig, J. M., Smith, L. L., Kan, G. y Van Lier, J. E."Sterol metabolism. XX. Cholesterol 7B-hydroperoxide".- J. Org. Chem. 38 (1973) 119.

76. Tsai, L. S. y Hudson, C. A.- "High performance liquid chromatography of oxygenated cholesterols and related compounds".J. Am. Oil. Chemists' Soc. 58 (1981) 931.

77. Tsai, L. S. y Hudson, C. A.- "Cholesterol oxides in commercial dry egg products: Isolation and identification".- J. Food Sci. 49 (1984) 1245

78. Tsai, L. S. y Hudson, C. A.- "Cholesterol oxides in commercial dry egg products: Quantitation".- J. Food Sci. 50 (1985) 229.

79. Tsai, L. S., Hudson, C. A., Ijichi, K. y Meehan, J. J.- " Quantitation of cholesterol $\alpha$-oxide in eggs by gas chromatography and high performance liquid chromatography".- J. Am. Oil Chemists' Soc. 56 (1979) 185A

80. Watabe, T., Kanai, M., Isobe, M. y Ozawa, N.- "Cholesterol $\alpha$ and $B$-epoxides as obligatory intermediates in the hepatic microsomal metabolism of cholesterol to cholestanetriol".- Biochim. Biophys. Acta 619 (1980) 414.

81. Yanishlieva-Maslarova, N. V. y Marinova, E. M.- "Autoxidation of sitosterol in lipid systems of different unsaturation degree".J. Am. Oil. Chemists' Soc. 62 (1985) 622.

(Recibido: Mayo 1990) 